\title{
PROCEDIMENTOS AVALIATIVOS NO CURSO DE SERVIÇO SOCIAL: O TRABALHO DE PORTFÓLIO
}

\author{
CURITIBA/PR MAIO/2018
}

\author{
Cleci Elisa Albiero - Uninter - cleci.a@uninter.com \\ Áurea Bastos Davet - Uninter - aurea.d@uninter.com \\ Tipo: Investigação Científica (IC) \\ Natureza: Descrição de Projeto em Andamento \\ Categoria: Pesquisa e Avaliação \\ Setor Educacional: EDUCAÇÃO SUPERIOR
}

\begin{abstract}
RESUMO
O reconhecimento do portfólio como um instrumento do processo formativo e avaliativo tem feito repensar sua importância e finalidade no curso de serviço social, tanto pelo viés da tutoria central como também pelo tutor orientador educacional que acompanha e orienta os alunos no desenvolvimento do trabalho, no polo de apoio presencial. Este trabalho visa problematizar o portfólio como instrumento do processo formativo e avaliativo. A pesquisa foi realizada entre os meses de dezembro de 2017 a fevereiro de 2018, tendo como objetivo a aproximação da compreensão dos tutores sobre o processo de avaliação do Portfólio, bem como captar elementos e subsídios para desencadear um processo de educação continuada tendo em vista a qualificação dos tutores para o exercício de atividades acadêmicas junto aos alunos do Curso de serviço social da UNINITER e o universo pesquisado foram os 119 tutores de serviço social e destes 49 responderam à pesquisa. O roteiro foi encaminhado via grupo de e-mail dos profissionais com acesso ao link do formulário google drive. Os resultados iniciais apontam que o portfólio é um importante instrumento de formação e avaliação para o aluno de serviço social, bem como permite a reflexão e abstração acerca dos conteúdos estudados nas disciplinas e as observações empíricas deste processo. Os desdobramentos em relação à pesquisa estão direcionados para a formatação de uma proposta de curso de formação continuada a estes profissionais
\end{abstract}

Palavras-chave: Serviço Social; Portfólio; Processos avaliativos; Formação; Tutoria 


\section{INTRODUÇÃO}

O presente trabalho tem como objetivo problematizar os procedimentos avaliativos no curso de serviço social e neste caso, o portfólio. Partindo de dados concretos, foi realizado uma pesquisa junto aos profissionais de serviço social que atuam diretamente no polo de apoio presencial, designados como tutores orientadores educacionais[1]. A busca pelas informações surgiu com o intuito de identificar de que forma os tutores orientadores educacionais de serviço social estavam percebendo a importância e a validade deste instrumento. $O$ estudo visa também identificar elementos e informações para capacitação, entendida como educação continuada, com estes tutores orientadores educacionais.

Questionamentos foram surgindo e, importante apontar algumas reflexões: como o tutor entende a função do portfólio no processo de formação do aluno de serviço social? Quais as dificuldades percebidas do aluno em relação à construção do portfólio? Como percebe, enquanto tutor, seu papel neste processo de formação? Como se estrutura o processo de avaliação do conteúdo trabalhado com o aluno, no contexto ensino aprendizado? Estas questões nortearam o processo da pesquisa e também da socialização dos resultados, os quais serão discutidos no decorrer deste trabalho.

Para desenvolvimento do proposto, a metodologia utilizada foi na busca do já produzido neste contexto, outro ponto foi à pesquisa com os tutores orientadores educacionais, por meio de um roteiro contendo questões abertas referentes ao tema em estudo. A mesma foi encaminhada via e-mail com acesso a um link do formulário do google drive contendo as questões propostas.

No desenvolvimento deste estudo, abordaremos sobre procedimentos avaliativos no curso de serviço social, neste momento especificamente o portfólio, conceitos, metodologia e significados, como instrumento acadêmico de formação e de avaliação. Propõe-se também um viés de reflexão deste instrumento enquanto uma ferramenta de aproximação com o processo de pesquisa acadêmica, tão cara a formação profissional do aluno. Por fim, as analises a esse tema se desenvolverão no contexto do curso de serviço social do Centro Universitário Internacional Uninter - Curitiba, PR, na modalidade EaD com a apresentação dos resultados da pesquisa.

\section{O PORTFÓLIO COMO PROCESSO DE AVALIAÇÃO E FORMAÇÃO ACADEMICA}

Partindo do debate sobre a formação acadêmica, a proposta aqui é pontuar elementos que subsidiem a reflexão em relação a formação e o processo avaliativo dos alunos do 
curso de bacharelado em serviço social.

Muito tem se falado sobre processos avaliativos, principlamente no ensino superior e de fato, este ainda é um tema que merece atenção no que condiz a vislumbrar possibilidades que amplie o processo de aprendizagem.

Ao se considerar o amplo cenário educacional, em especial do ensino e formação EaD e das metodologias ativas, a proposta refere-se ao portfólio como instrumento de formação e de avaliação dos alunos do curso de serviço social, e neste caso na modalidade à distância[2]. Para Torres, o termo portfólio, origina-se do italiano 'portafoglio', que significa "recipiente onde se guardam folhas soltas", começou a ser empregado em artes plásticas, em que o artista fazia uma seleção de trabalhos que exprimiam sua produção. (2008, p. 551) Porém aos poucos este conceito vem se modificando e compondo os processos e praticas educativas e avaliativas, nas escolas.

Neste contexto, o professor Ivo José Both, especialista na área de processos avaliativos, coloca que o "portfólio constitui-se no conjunto de produções resultantes das atividades do aluno, pelo menos uma por diciplina" ( 2012, p. 33)

Segundo Romanowski e Wachowicz ( 2006, p. 89 apud Both, 2012, p.31) a varias metodologias ou processos avaliativos, porém segundo os autores dois destacam-se como importante formas para este contexto, os quais seriam: a avaliação formativa (qualitativa) e somativa ( quantitativa), que segundo os autores, são duas formas que acompanha o aluno no seu processo de formação. Neste processo, uma não anula a outra, bem pelo contrário, são complementares e conservam caracteristicas individuais. Desta forma, afirmam as autoras,

\footnotetext{
[...] a avaliação formativa é a que procura acompanhar o desempenho do aluno no decorrer do processo de aprender e a somativa é a realizada no final desse processo e visa indicar os resultados obtidos para definir a continuidade dos estudos, isto é, indica se o aluno foiu ou não aprovado. (ROMANOWSKI E WACHOWICZ, 2006, p. 89 apud BOTH, 2012, p.31)
}

Este instrumento vem sofrendo modificações na sua estrutura e concepção justamente por entendermos como instrumento central para o processo de inserção do aluno na produção cientifica estimulando o exercício da pesquisa, procedimento fundamental para a sua formação acadêmica e o exercício profissional.

O processo investigativo é uma das atribuições evidenciadas no trabalho do assistente social e para o qual o aluno precisa ser constantemente instigado a desvendar e conhecer a realidade com a qual trabalhará no cotidiano profissional. Neste contexto, a 
pesquisa é "um instrumento de construção de conhecimentos no processo ensinoaprendizagem", Sá-Chaves (1998 apud AMBRÓSIO, 2013, p.25) que possibilita os primeiros contatos com a realidade vivenciada pelo aluno de serviço social e com as aproximações das expressões da questão social, objeto do trabalho e da intervenção profissional. É o momento da relação, de materalização, da teoria e sua subjetividade com o olhar para a realidade concreta da sociedade, das suas formas organizativas e da reflexão na ação.

O Portfólio no curso de Serviço Social da UNINTER compõe o processo de avaliação juntamente com outras três atividades de avaliação: a prova objetiva e a prova discursiva e as atividades pedagógicas on-line (APOL). Ao Portfólio cabem 30\% (trinta por cento) do total da nota final, sendo este valor composto por $60 \%$ do trabalho escrito e $40 \%$ na apresentação oral no polo de referencia. Neste processo avaliativo, os alunos elaboram um trabalho escrito relacionando as disciplinas ofertadas nos Módulos específicos. Portanto, é uma atividade interdisciplinar. O tema a ser estudado sempre está relacionado a assuntos comuns as disciplinas, de maneira que o aluno seja motivado a estudar com profundidade os conteúdos apresentados identificando temáticas transversais a estas e pesquisando no movimento real da sociedade contemporânea ou histórica, fatos que objetivem a discussão proposto, instigando desta forma os alunos a pesquisar fontes diversificadas, sejam com fundamentos teóricos, documentos complementares que discutam as expressões da questão social com as quais se confrontarão no exercício da profissão escolhida ou mesmo no contato com o trabalho do assistente social.

A construção deste trabalho, no entanto, desenvolve habilidades e reafirma competências profissionais sobre as quais se debruçam os professores e tutores na condição de orientadores do processo de compreensão da relevância deste instrumento avaliativo.

Assim, a pesquisa junto aos tutores orientadores educacionais emerge da necessidade de qualificação para apreensão do portfólio para além de um instrumento mecânico de avaliação, mas sim, potencializá-lo ao máximo dentro desta visão formativa profissional.

\section{PROCEDIMENTOS METOdOLÓGICOS}

A pesquisa foi realizada entre os meses de dez. de 2017 a fev. de 2018 com a participação de 119 profissionais, dos quais 49 responderam à pesquisa. Os norteadores da realização da pesquisa foram: problematizar os procedimentos avaliativos no curso de serviço social e neste caso, o portfólio; identificar se os tutores 
estavam percebendo a importância do mesmo como instrumento de formação e de avaliação; identificar elementos e informações para uma capacitação aqui entendida como educação permanente com os tutores e corretores de portfólio.

Trata-se de uma pesquisa de cunho qualitativo, exploratório com pesquisa bibliográfica, documental e de campo. Utilizou-se como instrumental de coleta de dados, um roteiro semi-estruturado contendo questões abertas, onde o participante puderam descrever seu entendimento e percepções referentes ao tema proposto. Como se trata de um tema de seus conhecimentos, as respostas foram desenvolvidas a partir das percepções e vivencias dos sujeitos envolvidos.

Para análise e interpretação dos dados coletados, utilizou-se a análise de conteúdo que segundo Triviños (2007, p. 159) "este método de análise se presta para o estudo das motivações, atitudes, valores, crenças, tendências" e também para o desvendar das ideologias que não se apresentam com a devida clareza na construção das ideias.

Estes subsídios somados as evidências e acompanhamento do processo permitem o aprofundamento, suas contradições e seus relacionamentos com as dinâmicas existentes no processo ensino/aprendizagem.

\section{RESULTADOS E DISCUSSÕES}

O lócus territorial para levantamento dos dados foram os profissionais assistentes sociais tutores orientadores educacionais do curso de bacharelado em Serviço Social do Centro Universitário Internacional Uninter na modalidade à distância. Participaram da pesquisa, 119 tutores orientadores educacionais, destes 49 responderam o roteiro perfazendo um total de $41,17 \%$.

Os resultados apontam que os tutores percebem o portfólio como uma importante ferramenta de formação e de desenvolvimento de competências e habilidades no aluno em formação; apresenta-se também como um importante instrumento para a construção do saber e desenvolvimento do conhecimento, aprendizagem e pesquisa. Como estratégia de formação, precisa ser reavaliado e proposto com novos formatos para que o aluno tenha melhor entendimento e que o perceba como estratégia de ensino e aprendizagem e não apenas como mais um trabalho a ser cumprido para obtenção de nota.[3]

Fundamental neste contexto, analisar o que dizem os tutores orientadores educacionais em relação a como ele, sujeito que participa deste processo de formação, entende a 
função do portfólio na formação. As falas dos sujeitos são representativas quando avaliam a importância do portfólio na formação do aluno, "[...]importante instrumento de avaliação, para acompanhar o desenvolvimento do aluno, além de prepara-lo para desempenhar um bom papel na sua carreira profissional, pois estará utilizando muita a escrita, pesquisas, relatórios e outros". (respondente A)

Outra questão emergente identificada nas respostas foi à compreensão do portfólio como um instrumento de formação para desenvolver no aluno as habilidades e a própria identidade profissional, "é um instrumento que possibilita o aluno conhecer e relatar sobre determinado assunto [....]" (respondente C).

Como nos aponta outro tutor orientador educacional, em relação a esse processo, que "[...] através da leitura o aluno exercitará o processo da escrita que se configura um dos principais recursos do assistente social" (respondente D). Além deste contexto da leitura e da escrita, fica evidente também a caracterização do portfólio como elemento de aproximação e inserção do aluno na pesquisa e na produção acadêmica, "[...]fundamental para o início da produção científica[...]" (respondente E)

A observação do papel do portfólio no desenvolvimento da consciência crítica, como nos aponta a tutora a seguir "Entendo como uma fonte de conhecimento, pesquisa, formação e desenvolvimento para a análise crítica do aluno". (respondente F).

A interdisciplinaridade é outra categoria identificada na fala dos sujeitos de pesquisa, pois "Exibe a compreensão do aluno acerca dos temas abordados nas disciplinas; exige que o mesmo interprete os conteúdos e identifique a conexão entre os assuntos abordados". (respondente $\mathrm{H}$ ).

Uma das dificuldades percebidas pelo tutor em relação à construção do trabalho está no fato do relatado acima acerca do peso atribuído (nota) na avaliação final. Relata o profissional, "Na minha turma mais da metade alegam que o portfólio vale muito pouco ponto na média final e por isso não se esforçam para fazer um trabalho bem desenvolvido e/ou simplesmente não fazem". (respondente B)

Zanellato em seu estudo sobre o portfólio como instrumento de avaliação traz em sua reflexão Anastasiou e Alves (2003, p. 109) os quais analisam esse instrumento sobre a ótica da "nota", uma das questões apontadas reside em entender o portfólio não como um produto avaliativo, mas sim como um processo de aprendizado. E o quanto esse pensamento do aluno ainda reflete o "arcaísmo, a repressão e a exclusão" exercitados na academia onde a prevalência da nota era a demonstração do saber adquirido e 
abstraído pelo aluno. (ZANELLATO, 2008, p. 22). Isso nos mostra o quanto ainda temos que avançar na visão conservadora dos processos avaliativos.

As falas descritas acima, representa claramente o processo de aprendizagem do aluno centrado apenas no valor da nota sem levar em consideração o processo de formação, reflexão construção de um saber referente a realidade vivenciada.

Both (2011, p. 37) nos coloca que "como instrumento privilegiadamente auxiliar do ensino, necessitamos encarar a avaliação como processo de desenvolvimento técnico, pedagógico, cientifico e psicológico do aluno em função da aprendizagem". Desta forma, o autor nos coloca que precisamos entender a avaliação, educador versus educando como indo além de simplesmente atribuir uma nota, deve-se entender o processo avaliativo como uma oportunidade, um passo para a formação e construção de um saber.

Aqui também, fica subentendido o nível de interação existente entre o tutor orientador educacional e o aluno. Para Ávila (1972, p. 77 apud Both 2011, p. 43) a avaliação "é a ação de apreciar em seu justo valor um ser, situação, atitude ou sentimento, considerando de modo objetivo os fatores ou elementos de que são constituídos".

Percebe-se muitas vezes que, no processo de avaliação, uma das maiores dificuldade do aluno é o entendimento no que está sendo solicitado, baixa percepção e o processo de síntese, resultado de uma formação primaria e secundaria de baixa qualidade onde leva o aluno a chegar ao ensino superior com dificuldades básicas de leituras, compreensão e abstração de texto. Outro ponto indicado pelos respondentes é "a dificuldade em dialogar com os autores de maneira critica e argumentativa", esses fatores levam a questões de deficiência no processo de aprendizagem e por sua consequentemente no processo avaliativo.

Um ponto fundamental a entender e que também foi elemento da pesquisa, como o tutor orientador educacional compreende seu papel no processo de formação, na atividade do portfólio? As diversas visões apresentadas demonstram a aproximação do tutor com o aluno, porém nem sempre esta tentativa se concretiza.

Como nos relata uma tutora orientadora educacional, "meu papel, enquanto tutora, é o de orientar o aluno a entender e desenvolver o trabalho de portfólio, discutindo junto com o mesmo todos os passos do trabalho". (respondente $\mathrm{C}$ )

Esta deveria ser uma busca constante do aluno, procurar o polo de apoio presencial 
para receber orientações e auxilio nas atividades de construção do trabalho, como também nas atividades de estudo. Este processo aproxima o tutor do aluno, no desenvolvimento, na formação e construção da identidade profissional.

O tutor também tem papel de despertar e orientar no aluno o interesse pela pesquisa, produção cientifica, espaços de participação coletiva da categoria profissional e de controle social "importante para direcionar o potencial do aluno e oferecer orientações acerca das estratégias de pesquisa". (respondente E)

Por fim, com base nos relatos e analises desenvolvidas e das demandas percebidas nos canais da tutoria central, elaborou-se uma proposta de educação continuada aos profissionais com o objetivo de provocar reflexões e promover interrogações de sentido e efetividade onde "o conhecimento se transforma em ação e a ação transformadora convertendo-se em conhecimento". (MAIA, BARBIANI, 2004, p. 29).

Segundo Barroco, a educação continuada é um compromisso forjado no Código de Ética Profissional quando trata da qualificação permanente dos serviços prestados, com o aprimoramento intelectual na perspectiva de afirmação das competências profissionais. (2012, p. 130) Esse compromisso dever ser materializado no âmbito da academia onde a docência se transforma em um espaço sócio ocupacional do assistente social, e para o qual precisa ser constantemente qualificado nas habilidades e atribuições, e aqui o objetivo esta no processo formativo profissional.

\section{CONSIDERAÇÕES FINAIS}

A pesquisa ora apresentada não pretendeu esgotar a discussão do Portifólio como instrumento de avaliação no processo formativo do aluno em serviço social, intencionou sim, abrir um espaço de discussões e reflexões acerca do compromisso do tutor orientador educacional em suas atribuições junto ao aluno de graduação e do desdobramento no execrício profissional a partir dos processos avaliativos demandandos na academia em seu processo de formação em diferentes territórios e lugares.

Categorias importantes foram evidenciadas nas respostas dos sujeitos: a expressão livre do aluno, a oprtunidade de exercitar as práticas de escrita, discursiva e crítica na composião do trabalho acadêmico, a percepção da interdisciplinaridade, o controle docente empoderado pela emissão de uma nota para produção apresentada. Isso retrata elementos necessário e urgentes para ampliar a reflexão sobre o papel do tutor e do docente em suas salas de aula e das propriedades que exercem em todas as fases 
do processo de formação profissional.

A proposta de capacitação permanente junto aos tutores significa, para além da qualificação profissional no âmbito da educação, um compromisso e um respeito ético das coordenações de cursos com aqueles que se dispõem a construir um novo modelo de educação com responsabilidade e possibilidades na afirmação de uma sociedade mais humana e justa, com instrumentos e fundamentos teóricos, metodológios, técnicos, científicos e ético.

Ou seja, como nos diz BARROCO, "no contexto da sociedade capitalista, em face da apropriação privada dos meios de produção e das formas pelas quais se objetiva a (re)produção da vida social[...]" (2003, p. 33), a qualificação dos profissinais pode representar a possibilidade de construção da sociabilidade da humanização utilizando a nosso favor o que a inteligência humana nos coloca disponivel cotidianamente em nosso trabalho: as tecnologias da comunicação para a educação.

\section{REFERÊNCIAS}

BARROCO, M. L. S. Código de ètica do(a) Assistente Social comentado. São Paulo. Cortez: 2012.

BARROCO, M. L. S. Ética e Serviço Social: fundamentos ontológicos. São Paulo. Cortez: 2003.

BOTH, I. J. Avaliação: "voz da consciencia" da aprendizagem. 2-ed. Rev., atual. E ampl. - Curitiba: Ibpex, 2012

MAIA, M.; BARBIANI, R. A formação continuada em serviço social: uma experiencia em construção. Porto Alegre: EDIPUCRS, 2004.

ROMANOWSKI, J. P. Formação e profissionalização docente. 4.ed.rev. - Curitiba: Ibpex, 2010

TORRES, S. C. G. Portfólio como instrumento de aprendizagem e suas implicações para a prática pedagógica reflexiva. Rev. Diálogo Educ., Curitiba, v.8, n.24, p.549-561, maio/ago. 2008.

TRIVINOS, A. N. S. Introdução a Pesquisa em Ciências Sociais: Pesquisa Qualitativa em Educação. São Paulo: Atlas, 2008. 
ZANELLATO, J. R. Portfólio como instrumento de avaliação no ensino de Graduação Artes Visuais. Dissertação de Mstrado apresentada na Pontifícia Universidade Católica de Campinas. PUC/Campinas. 2008. Disponível em http://www.bibliotecadigital.puc-

campinas.edu.br/tde_arquivos/3/TDE-2008-02-26T073826Z-

391/Publico/Jose\%20Roberto\%20Zanellato.pdf

[1] Orientador educacional é a denominação formal utilizada pela instituição para contratação dos profissionais nos Polos presenciais que exercem as atribuições específicas de tutores no desenvolvimento e monitoramento das atividades acadêmicas dos alunos nos cursos de nível superior.

[2] O Portfólio é uma atividade acadêmica tradicionalmente utilizada nos processos avaliativos de cursos superiores da UNINTER, como por exemplo, na área de Educação. Cada curso, no entanto, desenvolve as atividades dentro de seus interesses e especificidades. No curso de Bacharelado em Serviço Social à distância essa atividade avaliativa é denominada Portfolio. Na modalidade presencial, denomina-se Problematização Baseada em Problemas (PBL), sendo definida como uma disciplina na matriz curricular.

[3] A partir deste dado da pesquisa, o Portfólio que somava apenas $10 \%$ da nota do processo avaliativo, passou a compor $30 \%$ do total da nota final. Somando-se ao trabalho escrito a apresentação oral. Já se observou significativos resultados na apropriação dos conteúdos estudados e na melhoria da qualidade dos trabalhos apresentados. 